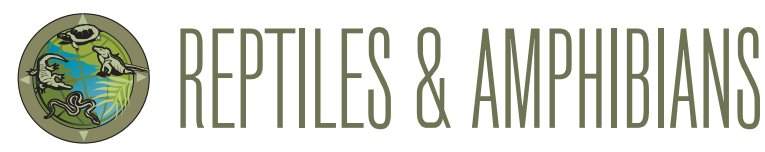

\title{
Intertidal Beach Foraging by \\ Black Spiny-tailed Iguanas (Ctenosaura similis) and Green Iguanas (Iguana iguana) in southern Florida
}

\author{
Andrew I. Furness \\ Miami Beach, Florida, USA (afurness001@gmail.com)
}

Photographs by the author.

$\mathrm{H}$ erbivory is rare among lizards - found in only $2 \%$ of species - yet commonplace in the family Iguanidae (Iverson 1982; Janzen and Brodie 1995; Cooper and Vitt 2002). Even rarer still is marine herbivory, found in a single species - the iconic Galapagos Marine Iguana (Amblyrhynchus cristatus) (Dawson et al. 1977; Trillmich and Trillmich 1986). Marine Iguanas graze on marine algae in the intertidal zone and coastal waters (Trillmich and Trillmich 1986; Wikelski and Trillmich 1994). Intertidal foraging, or its behavioral precursors, is either unknown or poorly described in other (related) species of iguanas. Three introduced species of iguanas are established in southern Florida, and two of those species are common (Townsend et al. 2003). The Black Spiny-tailed Iguana (Ctenosaura similis), native to Mexico and Central America, was first introduced into southern Florida in 1979, and subsequently established populations on both the Gulf and Atlantic Coasts (Krysko et al. 2003, 2009; Avery et al. 2014). The Green Iguana (Iguana iguana), with an extensive Neotropical distribution, was first introduced into southern Florida in the early 1960s, and has established populations throughout the southern half of the state (Townsend et al. 2003). These two introduced species co-occur on Key Biscayne, a low-lying barrier island south of Miami Beach, Miami-Dade County, Florida. Green Iguanas are almost entirely herbivorous, whereas Black Spiny-tailed Iguanas are omnivorous (Montanucci 1968; Fitch and Henderson 1978; Krysko et al. 2009). Herein I present information on active intertidal foraging by Black Spiny-tailed Iguanas and Green Iguanas that might have implications for island colonization and the evolution of marine herbivory in Galapagos Marine Iguanas.

\section{Observations}

On three separate occasions (afternoon of 28 August, morning of 2 September, and morning of 4 September 2021), I visited a relatively secluded section of beach on Key Biscayne

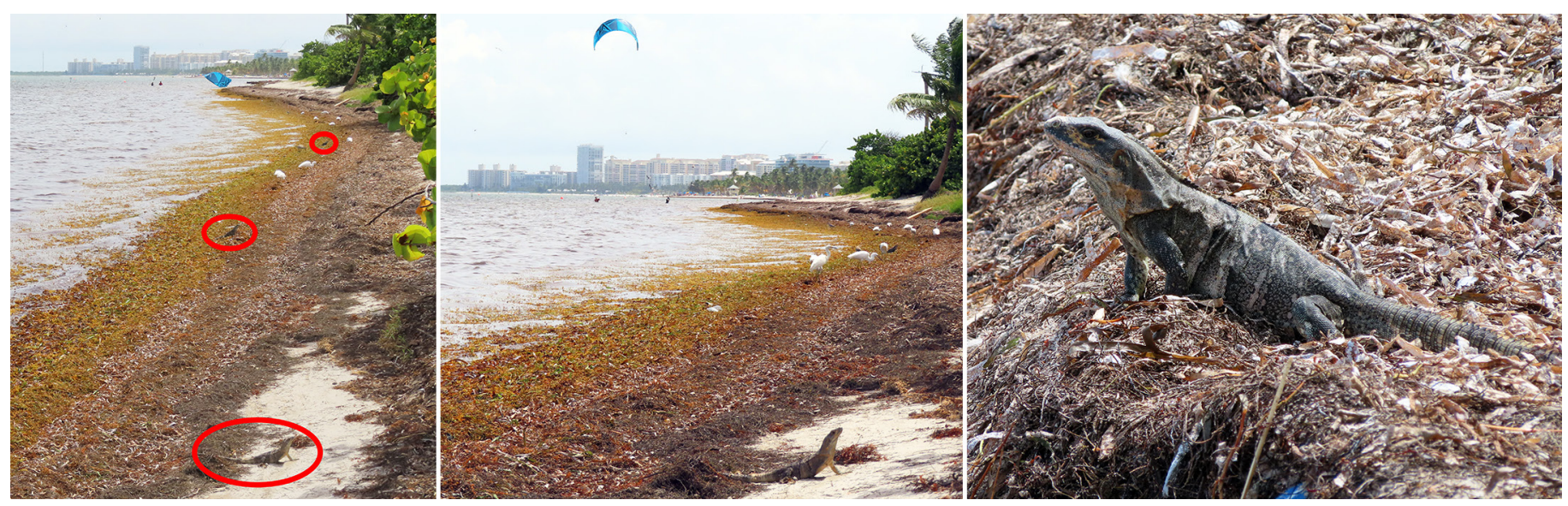

Fig. 1. Black Spiny-tailed Iguanas (Ctenosaura similis) forage in seagrass in the intertidal beach zone of the northernmost section of Crandon Beach, Key Biscayne, Florida, at 1505 h on 28 August 2021. 
(25.720333, -80.148051) where I observed dozens of Black Spiny-tailed Iguanas, including juveniles (which are green), subadults, and adults, foraging in the beach's intertidal zone (Figs. 1-3, 5-8). They were at the vegetation line, on the sand, and in the abundant brown seagrass that had washed ashore. The seagrass had formed a thick brown line on the beach, referred to as the wrack line, just above the high-tide mark. The wrack line on Key Biscayne comprises mostly Sargassum or Gulfweed (Sargassum spp.) from far offshore mixed with seagrasses from shallow coastal waters. I observed clear foraging behavior by Black Spiny-tailed Iguanas along the wrack line. This was characterized by quick rapid movements, stopping, bending down, biting, smacking the jaws, and swallowing. Smaller individuals might have been targeting amphipods, which were extremely abundant. One adult clearly consumed three large green seeds (Figs. 5-6). On several occasions, subadults and adults were smacking their lips with small pieces of vegetation emerging from their mouths. They apparently were targeting vegetation, but I cannot rule out the possibility that the grasses were picked up incidentally while biting other items. With the exception of the three large green seeds, I was unable to determine with certainty what

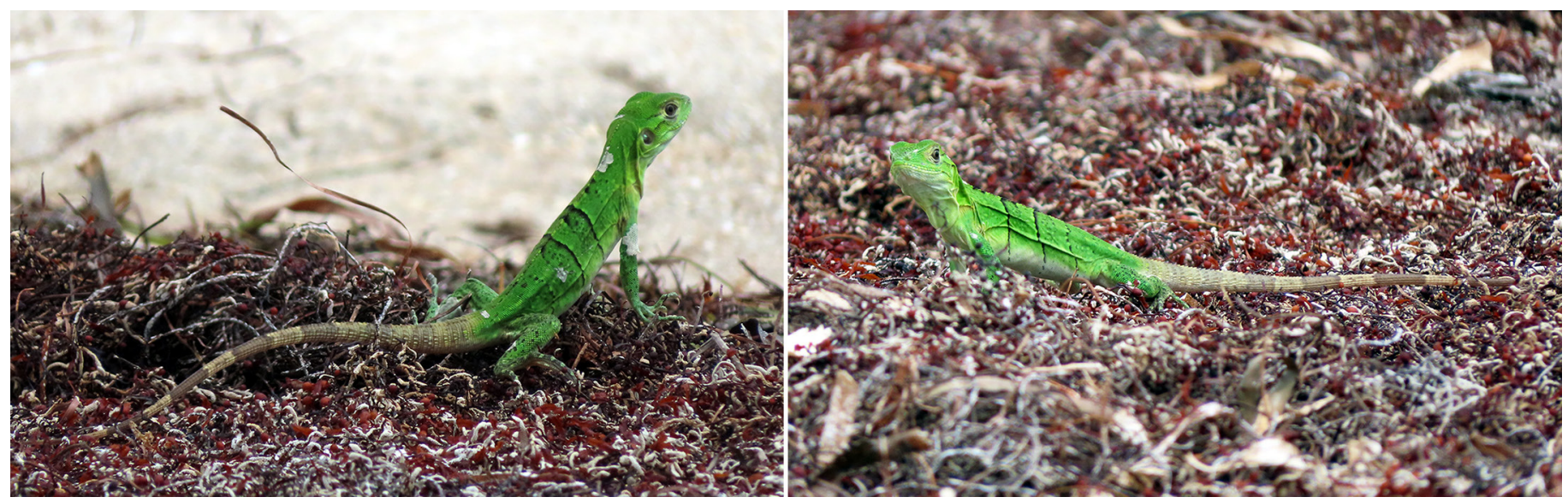

Fig. 2. Juvenile Black Spiny-tailed Iguanas (Ctenosaura similis) forage in seagrass in the intertidal beach zone of the northernmost section of Crandon Beach, Key Biscayne, Florida, at 1230 h on 2 September 2021.

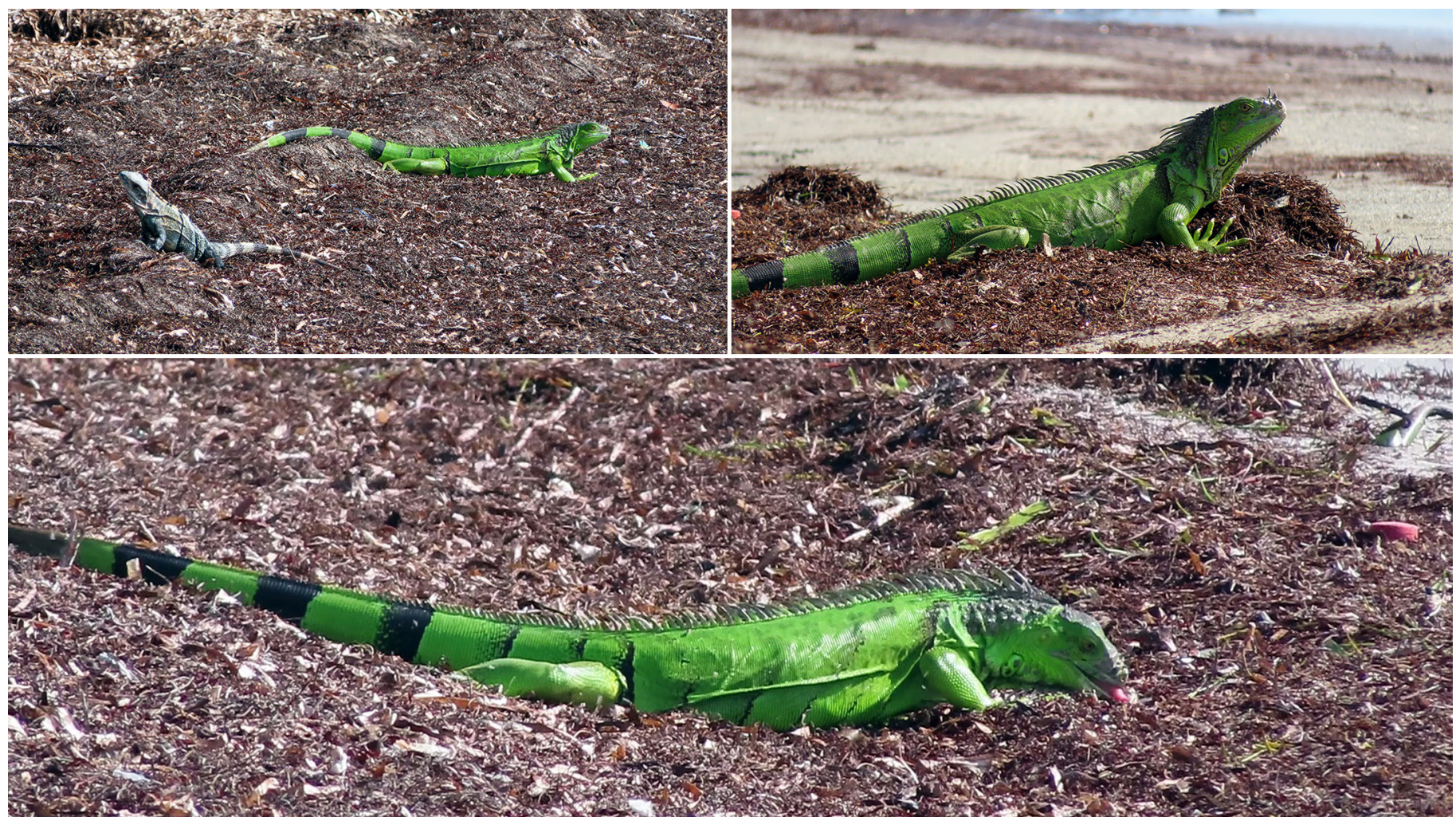

Fig. 3. A Black spiny-tailed Iguana (Ctenosaura similis) and a Green Iguana (Iguana iguana) forage in the intertidal beach zone of the northernmost section of Crandon Beach, Key Biscayne, Florida, at 940-954 h on 4 September 2021. 
exact items were ingested due to small size and the fact that items were very quickly picked from the dense seagrass and rapidly consumed.

Between 0940 and $0954 \mathrm{~h}$ on 4 September 2021, I observed two Green Iguanas, one adult and one subadult, foraging in the seagrass and on the sand below the wrack line (Figs. 3-4). They appeared to nibble and lick the seagrass and sand, although I could not determine what, if anything, was ingested. After $15 \mathrm{~min}$, they moved from the beach into bor- dering vegetation. These were the only Green Iguanas seen on the beach in over $4 \mathrm{~h}$ of observation on three different days, during which time I saw several dozen Black Spiny-tailed Iguanas foraging on this beach. These observations suggest that exploitation of the intertidal zone is a common foraging strategy in this population of Black Spiny-tailed Iguanas, and that it might be comparatively infrequent in Green Iguanas.

At $1051 \mathrm{~h}$ on 4 September, I observed an adult Ctenosaura similis foraging among the seagrass. It occasion-
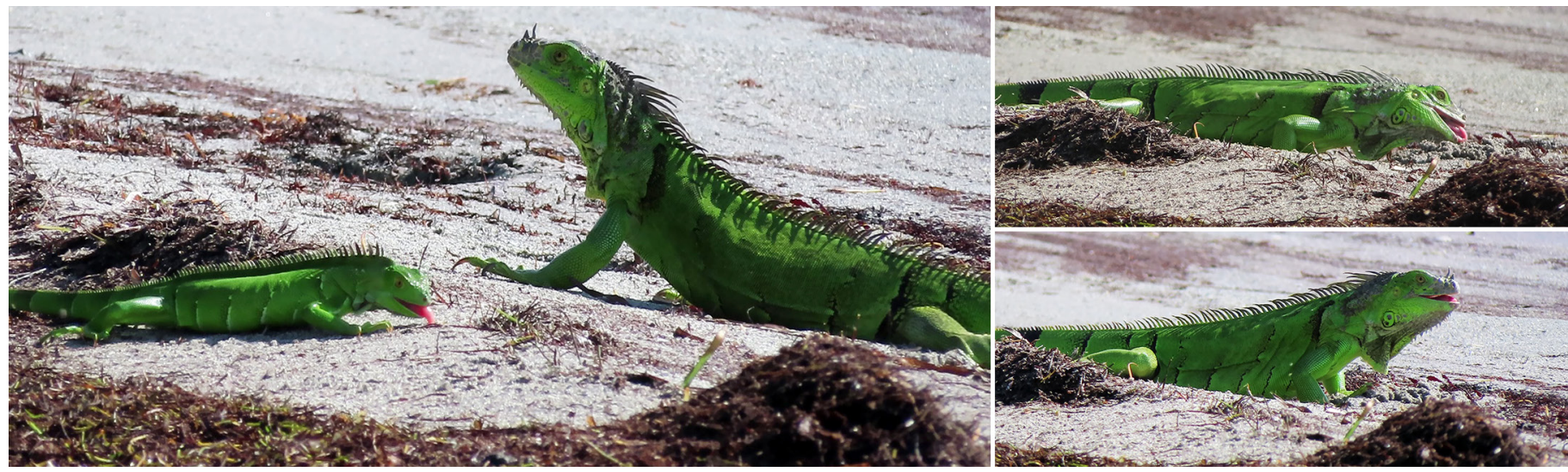

Fig. 4. Two Green Iguanas (Iguana iguana) forage in the intertidal beach zone of the northernmost section of Crandon Beach, Key Biscayne, Florida, at 0950-0952 h on 4 September 2021. A video is available at: https://youtu.be/xVYY3Sw6hy4.
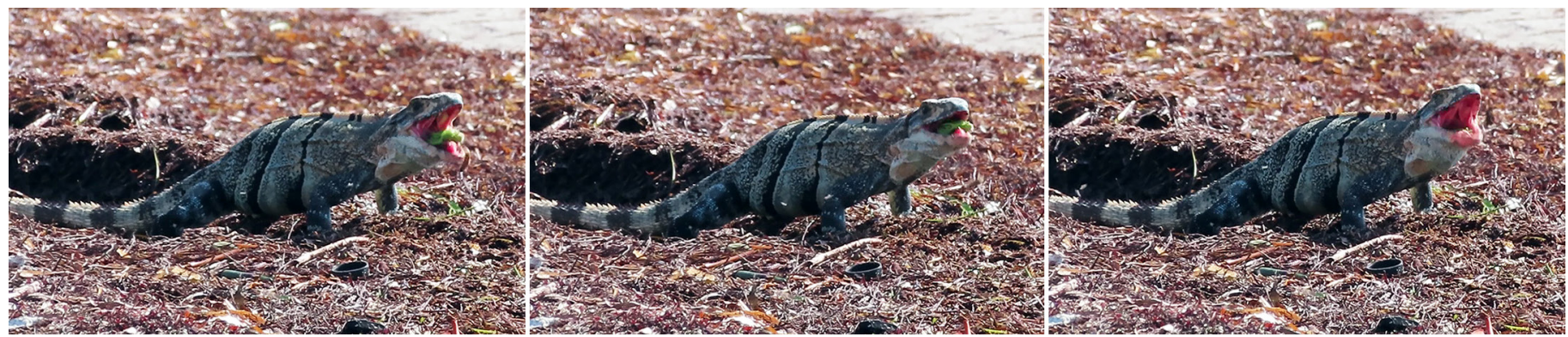

Fig. 5. An adult Black Spiny-tailed Iguana (Ctenosaura similis) consumes a large green seed picked from the seagrass in the intertidal beach zone of the northernmost section of Crandon Beach, Key Biscayne, Florida, at 1003 h on 4 September 2021. A video is available at: https://youtu.be/abZ2bl0Ho0Q.
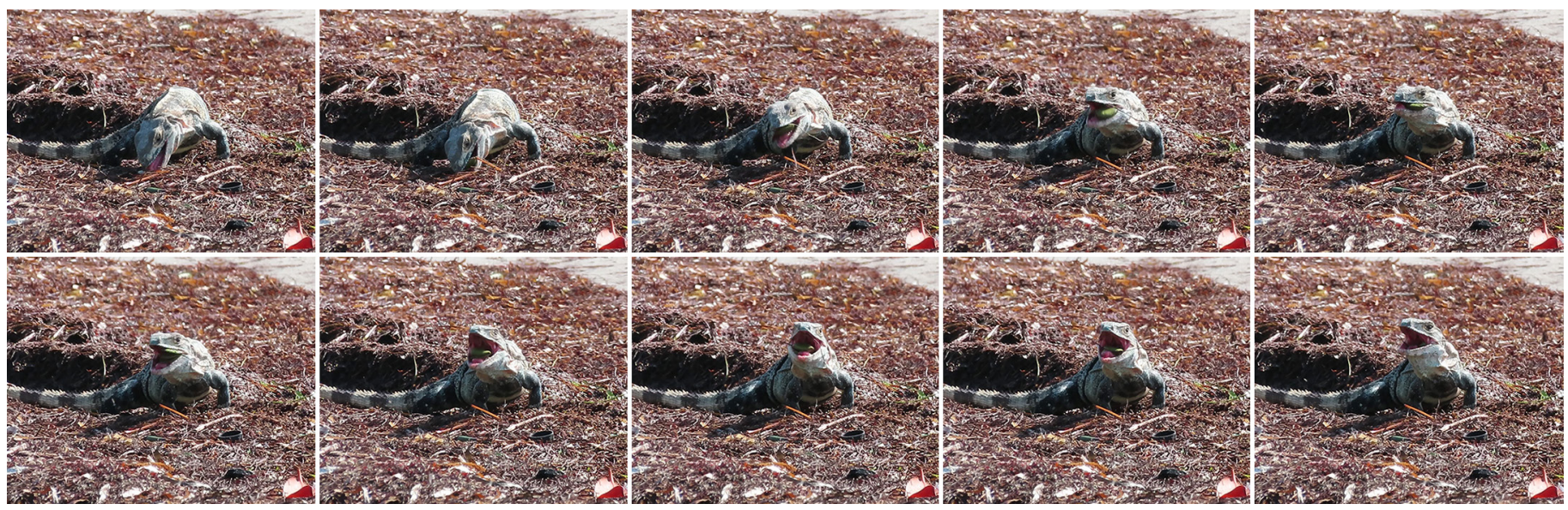

Fig. 6. An adult Black Spiny-tailed Iguana (Ctenosaura similis) consumes a large green seed picked from among the seagrass in the intertidal beach zone of the northernmost section of Crandon Beach, Key Biscayne, Florida, at $1004 \mathrm{~h}$ on 4 September 2021. The whole process took five seconds. A video is available at: https://youtu.be/abZ2bl0Ho0Q. 
ally stopped foraging, took up a prominent position, raised its body off the ground, and opened its mouth (Fig. 7) for several seconds to a minute before resuming foraging. I observed similar behavior in other individuals, including juveniles and subadults. In all instances, individuals that were exposed to full sun in the intertidal zone assumed somewhat prominent positions, elevated their bodies, remained stationary, and in some cases gaped. This might have been a thermoregulatory strategy with a prominent position maximizing exposure to the breeze, elevating the body increasing airflow, and gaping facilitating heat dissipation or allowing for panting (Loughran and Wolf 2020).
I observed intertidal foraging only on the relatively secluded northernmost part of Crandon Beach, which appeared to have a number of amenable features. Due to its inaccessibility (i.e., much greater distance from parking lots), this section is much less used than other parts of Crandon Beach. This beach was natural in the sense that seagrass was left in place and not cleared by machinery, as on most beaches in southern Florida. And finally, the natural vegetation was intact and began just above the high-tide line. Thus, the beach can be described as a strip of sand (the narrowness of which varied depending on the tide) covered by abundant seagrass and other flotsam (i.e., driftwood, trash, vegetation,

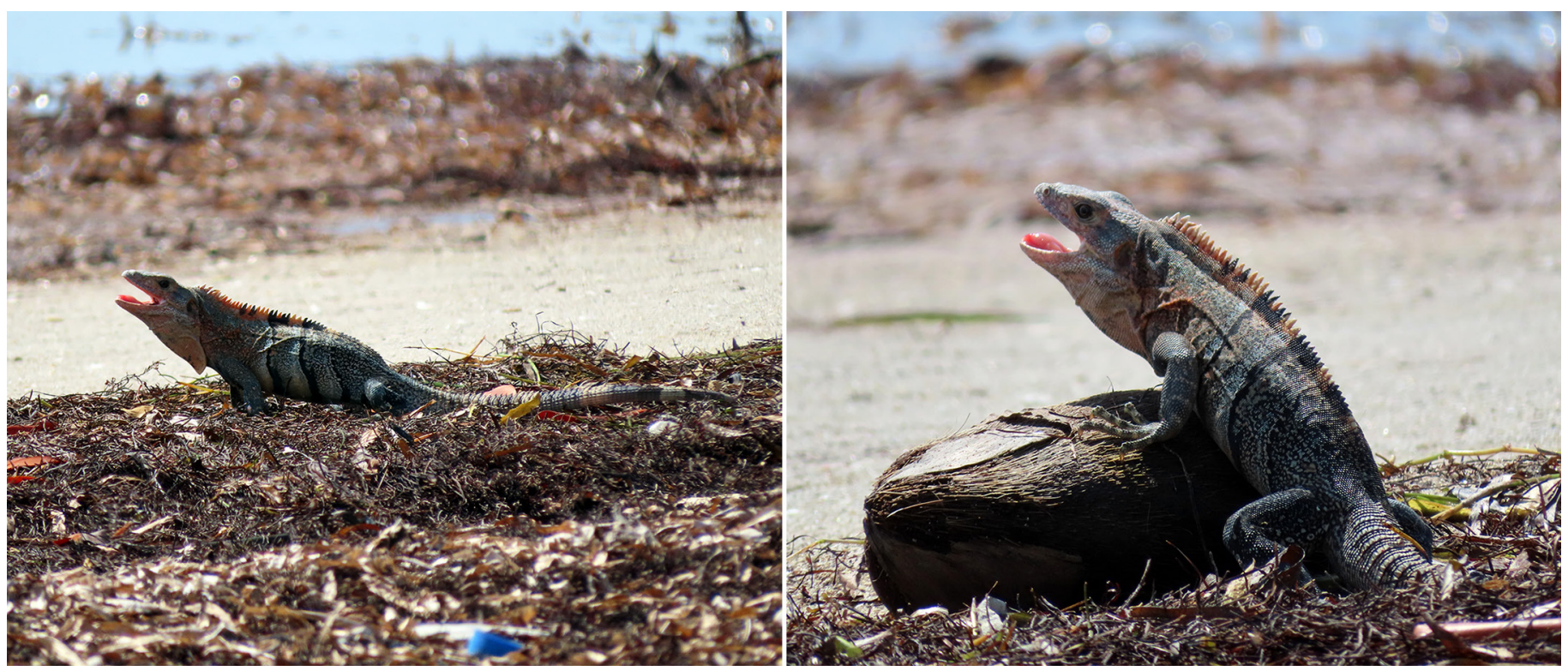

Fig. 7. At 1051-1056 h on 4 September 2021, an adult Black Spiny-tailed Iguana (Ctenosaura similis) gapes, perhaps to thermoregulate, while perched in an exposed location in the northernmost section of Crandon Beach, Key Biscayne, Florida. A video is available at: https://youtu.be/Sf18WUdMbxk.
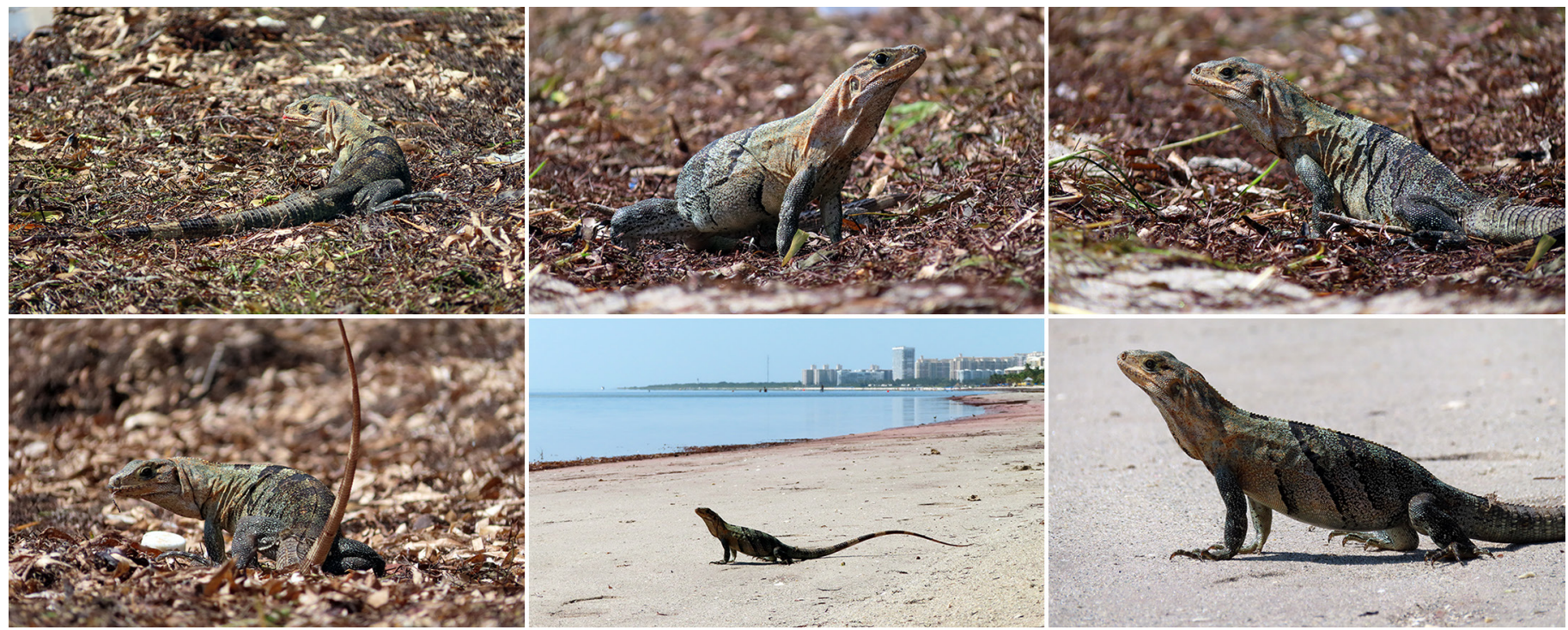

Fig. 8. At 1105-1113 h on 4 September 2021, a Black Spiny-tailed Iguana (Ctenosaura similis) forages among seagrass in the northernmost section of Crandon Beach, Key Biscayne, Florida, moves onto the sand at low tide, and then returns to forage. A video is available at: https://youtu.be/adLfhDBV_2U. 
seeds) and bordered by dense natural vegetation including trees. The latter allowed iguanas quick access to shade and provided a safe retreat when disturbed (for example, when a human walked by along the beach). While foraging in the exposed intertidal zone, Black Spiny-tailed Iguanas appeared quite vigilant. In particular, when a person approached walking along the beach, the iguanas quickly retreated into the nearby vegetation. This suggests that intertidal foraging might occur only under somewhat pristine conditions. Beaches that are heavily trafficked or substantially modified (i.e., bordering vegetation removed to create a greater expanse of sand and/or seagrass mechanically removed) might not be suitable. Finally, Key Biscayne's geographic location as an exposed barrier island subject to abundant seagrass and other material being continually washed ashore likely provide particularly good foraging opportunities compared to more sheltered beaches.

In their native range, Black Spiny-tailed Iguanas tend to be found in relatively open environments near coasts, and are particularly abundant in environments modified by humans (Fitch and Henderson 1978), but I am aware of only one report of intertidal foraging. Arndt (1999) described a Black Spiny-tailed Iguana actively hunting and consuming a painted ghost crab on a beach in Costa Rica.

\section{Discussion}

Galapagos Land Iguanas (Conolophus spp.) and Marine Iguanas diverged approximately 4.5 million years ago, likely after their common ancestor arrived in the archipelago by rafting from Central America (MacLeod et al. 2015). Spinytailed Iguanas (genera Ctenosaura and Cachryx) are the closest living relatives of Galapagos Iguanas (land and marine) and last shared a common ancestor $\sim 8.3$ million years ago (MacLeod et al. 2015; Malone et al. 2017). Marine Iguanas are famous for their unique diet of macrophytic marine algae, which they graze from the intertidal zone, and, in the case of large males, by diving and grazing while submerged at depths to $12 \mathrm{~m}$ (Dawson et al. 1977; Trillmich and Trillmich 1986; Wikelski and Trillmich 1994). Many of the adaptations found in Galapagos Marine Iguanas are not unique to that species but found to a comparable or slightly less welldeveloped extent in other terrestrial iguanids; these include circulatory responses to diving, swimming and diving abilities, tolerance of submergence, and nasal salt secreting glands (Templeton 1967; Dawson et al. 1977; Berry et al. 2021). Dawson et al. (1977) stated that the majority of specialization seen in Marine Iguanas appears to be behavioral (i.e., the recognition of macrophytic algae as food and tolerance of high densities of conspecifics on the shoreline) with Marine Iguanas appearing as "member[s] of a terrestrial line that was preadapted for exploiting a unique combination of circumstances.”
My observations of intertidal foraging in the Black Spinytailed Iguana (Ctenosaura similis) indicate this behavior is not unique to marine iguanas. Whether intertidal foraging is more widely distributed - in other populations of Ctenosaura similis, other species of Ctenosaura, or even more broadly in the family Iguanidae - is deserving of further investigation. Specifically, if both a herbivorous diet and intertidal foraging were present in the common ancestor of the clade, it could represent a potential behavioral pre-adaptation toward the consumption of marine algae.

Species in the family Iguanidae, including those in the genera Iguana and Ctenosaura, occur naturally on a variety of islands. For example, Ctenosaura similis, in addition to being found near the Atlantic and Pacific Coasts from the Yucatan Peninsula in Mexico to Panama, has been recorded on Caribbean islands, including Cozumel, Utila, Guanaja, Providencia, San Andrés, and the Corn Islands (K. de Queiroz 1995; Hollingsworth 2004), and on Pacific islands, including the Fonseca and Pearl Islands (K. de Queiroz 1995; Hollingsworth 2004; McCranie and Gutsche 2016). I suggest living in vegetation just above the high-tide line and foraging in the intertidal zone could lead to an increased likelihood of being washed out to sea and cast adrift during tropical storms, ultimately leading to the colonization of islands. Over-water dispersal via rafting is thought to be the means by which iguanas (and many other species) colonized islands that were never connected to the mainland (e.g., A. de Queiroz 2005; Ali and Fritz 2021). Indeed, Censky et al. (1998) described how, after a series of Caribbean hurricanes in 1995, Green Iguanas arrived on the island of Anguilla: "On 4 October 1995, at least 15 individuals of the Green Iguana, Iguana iguana, appeared on the eastern beaches of Anguilla in the Caribbean. This species did not previously occur on the island. They arrived on a mat of logs and uprooted trees, some of which were more than 30 feet long and had large root masses. Local fishermen say the mat was extensive and took two days to pile up on shore." Similarly, four days after a tropical storm, boaters found an adult Baja California Spiny-tailed Iguana (Ctenosaura hemilopha) on a piece of driftwood floating in the Sea of Cortez. The lizard, which appeared to be healthy, was at least $24 \mathrm{~km}$ from the probable mainland source (near $\mathrm{La} \mathrm{Paz}$ ) and $7 \mathrm{~km}$ from the nearest island (Cerralvo Island) (Cook and Haussler 2013).

\section{Literature Cited}

Ali, J.R. and U. Fritz. 2021. Origins of Galápagos' land-locked vertebrates: what, whence, when, how? Biological Journal of the Linnean Society 134: 261-284. https://doi.org/10.1093/biolinnean/blab085.

Arndt, R.G. 1999. Predation by the black iguana (Ctenosaura similis) on the painted ghost crab (Ocypode gaudichaudii) in Costa Rica. Florida Scientist 62: 111114.

Avery, M.L., E.A. Tillman, C. Spurfeld, R.M. Engeman, K.P. Maciejewski, J.D. Brown, and E.A. Fetzer. 2014. Invasive black spiny tailed iguanas (Ctenosaura similis) on Gasparilla Island, Florida, USA. Integrative Zoology 9: 590-597. 
https://doi.org/10.1111/1749-4877.12085.

Berry, K.A., J.P. Muñoz-Pérez, C.P. Vintimilla-Palacios, and C.J. Clemente. 2021. Morphological and performance modifications in the world's only marine lizard, the Galápagos marine iguana, Amblyrhynchus cristatus. Biological Journal of the Linnean Society 133: 68-80. https://doi.org/10.1093/biolinnean/blab002.

Censky, E.J., K. Hodge, and J. Dudley. 1998. Over-water dispersal of lizards due to hurricanes. Nature 395: 556. https://doi.org/10.1038/26886.

Cook, D.G. and D. Haussler. 2013. Ctenosaura hemilopha (Baja California Spinytailed Iguana). Dispersal phenomenon. Herpetological Review 44: 321-322.

Cooper, W.E., Jr., and L.J. Vitt. 2002. Distribution, extent, and evolution of plant consumption by lizards. Journal of Zoology 257: 487-517. https://doi. org/10.1017/S0952836902001085.

Dawson, W.R., G.A. Bartholomew, and A.F. Bennett. 1977. A reappraisal of the aquatic specializations of the Galapagos marine iguana (Amblyrhynchus cristatus). Evolution 31: 891-897. https://doi.org/10.2307/2407452.

de Queiroz, A. 2005. The resurrection of oceanic dispersal in historical biogeography. Trends in Ecology \& Evolution 20: 68-73. https://doi.org/10.1016/j. tree.2004.11.006.

de Queiroz, K. 1995. Checklist and key to the extant species of Mexican iguanas (Reptilia: Iguaninae). Publicaciones Especiales del Museo de Zoologia, Universidad Nacional Autonoma de Mexico 9: 1-48.

Fitch, H.S. and R.W. Henderson. 1978. Ecology and exploitation of Ctenosaura similis. The University of Kansas Science Bulletin 51: 483-500. https://doi. org/10.5962/bhl.part.17246.

Hollingsworth, B.D. 2004. The evolution of iguanas: an overview of relationships and a checklist of species, pp. 19-44. In: A.C. Alberts, R.L. Carter, W.K. Hayes, and E.P. Martins (eds.), Iguanas: Biology and Conservation. University of California Press, Berkeley, California, USA.

Iverson, J. B. 1982. Adaptations to herbivory in iguanine lizards, pp. 60-76. In: G.M. Burghardt and A.S. Rand (eds.), Iguanas of the World. Their Behavior, Ecology and Conservation. Noyes Publications, Park Ridge, New Jersey, USA.

Janzen, F.J. and E.D. Brodie. 1995. Visually-oriented foraging in a natural population of herbivorous lizards (Ctenosaura similis). Journal of Herpetology 29:
132-136. https://doi.org/10.2307/1565099.

Krysko, K.L., F.W. King, K.M. Enge, and A.T. Reppas. 2003. Distribution of the introduced black spiny-tailed iguana (Ctenosaura similis) on the southwestern coast of Florida. Florida Scientist 66: 141-146.

Krysko, K.L., K.W. Larson, D. Diep, E. Abellana, and E.R. McKercher. 2009. Diet of the nonindigenous black spiny-tailed iguana, Ctenosaura similis (Gray 1831) (Sauria: Iguanidae), in southern Florida. Florida Scientist 72: 458.

Loughran, C.L. and B.O. Wolf. 2020. The functional significance of panting as a mechanism of thermoregulation and its relationship to the critical thermal maxima in lizards. Journal of Experimental Biology 223: 1-11. https://doi. org/10.1242/jeb.224139.

MacLeod, A., A. Rodríguez, M. Vences, P. Orozco-terWengel, C. García, F. Trillmich, G. Gentile, A. Caccone, G. Quezada, and S. Steinfartz. 2015. Hybridization masks speciation in the evolutionary history of the Galápagos marine iguana. Proceedings of the Royal Society B: Biological Sciences 282: 1-9. https://doi.org/10.1098/rspb.2015.0425.

Malone, C.L., V.H. Reynoso, and L. Buckley. 2017. Never judge an iguana by its spines: Systematics of the Yucatan spiny tailed iguana, Ctenosaura defensor (Cope, 1866). Molecular Phylogenetics and Evolution 115: 27-39. https://doi. org/10.1016/j.ympev.2017.07.010.

McCranie, J.R. and A. Gutsche. 2016. The herpetofauna of islands in the Golfo de Fonseca and adjacent waters, Honduras. Mesoamerican Herpetology 3: 842-899.

Montanucci, R.R. 1968. Comparative dentition in four iguanid lizards. Herpetologica 24: 305-315.

Templeton, J.R. 1967. Nasal salt gland excretion and adjustment to sodium loading in the lizard, Ctenosaura pectinata. Copeia 1967: 136-140. https://doi. org/10.2307/1442186.

Townsend, J.H., K.L. Krysko, and K.M. Enge. 2003. Introduced iguanas in southern Florida: A history of more than 35 years. Iguana 10: 111-118.

Trillmich, K.G.K. and F. Trillmich. 1986. Foraging strategies of the marine iguana, Amblyrhynchus cristatus. Behavioral Ecology and Sociobiology 18: 259-266.

Wikelski, M. and F. Trillmich. 1994. Foraging strategies of the Galapagos marine iguana (Amblyrhynchus cristatus): adapting behavioral rules to ontogenetic size change. Behaviour 128: 255-279. 